\title{
Two-Stage Pricing Decision for Low-Carbon Products Based on Consumer Strategic Behaviour
}

\author{
Cheng Che, Zhihong Zhang $\mathbb{D}$, Xiaoguang Zhang $(\mathbb{D}$, and Yi Chen $\mathbb{1}$ \\ School of Economics and Management, China University of Petroleum, Qingdao 266580, China \\ Correspondence should be addressed to Xiaoguang Zhang; s20080060@s.upc.edu.cn
}

Received 5 November 2020; Revised 6 December 2020; Accepted 26 December 2020; Published 13 January 2021

Academic Editor: Wei Zhang

Copyright (c) 2021 Cheng Che et al. This is an open access article distributed under the Creative Commons Attribution License, which permits unrestricted use, distribution, and reproduction in any medium, provided the original work is properly cited.

\begin{abstract}
The development of information technology has changed the pricing strategy of retailers, and consumers have also made strategic consumption behaviours accordingly. At the same time, changes in the environment have caused changes in the retailer's products and raised consumers' environmental awareness. This paper uses a two-stage pricing model to study the low-carbon product pricing decisions of retailers based on strategic consumers with low-carbon preferences in two situations. Through the analysis of low-carbon and ordinary products in two situations, the following conclusions can be drawn: (1) In a market where retailers only sell low-carbon products, product prices and profits increase as consumers' green preference $\theta$ increases. (2) In the low-carbon product and ordinary product markets, the price and profit of low-carbon products increase with regard to consumers' green preference $\theta$. (3) In the second stage, when consumers' intertemporal discount factor $\beta$ for ordinary products is larger than that of low-carbon products, the retailer's total profit is smaller. The research conclusion comprehensively analyses the impact of customer strategic behaviour on the two-stage pricing decision of green differentiated products, which provides a very important reference for retailers to make pricing optimization decisions.
\end{abstract}

\section{Introduction}

With global warming and various environmental problems emerging in an endless stream $[1,2]$, the country has issued various related laws and policies to guide consumers and enterprises to conduct low-carbon environmental protection behaviours. In response to the national call for energy conservation and emission reduction, enterprises have developed energy-saving products. For consumers with lowcarbon awareness, they are more inclined to buy low-carbon products [3]. Studies by Laroche et al. show that more consumers are willing to support higher prices for green products [4]. According to the report of the current situation of China's public green consumption (2019 Edition), 83.34\% of the respondents expressed support for green consumption behaviour [5]. But for ordinary consumers, the functions of low-carbon products are the same as those of ordinary products [6], but the price is higher, so some consumers may not choose low-carbon products because of the slightly higher prices.
On the other hand, the construction and improvement of various information platforms enable consumers to learn about product attributes and price changes through various channels. Therefore, consumers choose to purchase products based on their own utility maximization, which reflects the nature of consumers' strategies [7, 8]. However, this behaviour will make retailers face the pressure of inventory and product updates. In order to alleviate the pressure, retailers will adopt measures such as price cuts and promotions, and customers will make strategic decisions based on the behaviour of the business. Therefore, retailers must take into account the strategic behaviour of consumers when making decisions to achieve their own maximum profits.

Previous research mainly focused on the coordinated pricing of a single low-carbon product supply chain. It did not consider the pricing of a single retailer in the case of product differences, and did not consider the impact of consumers' strategic behaviour on pricing. In the previous literature on the pricing of differentiated products, they generally focused on manufacturing and remanufacturing products and did not 
discuss the differential pricing of low-carbon and ordinary products. In addition, consumers' low-carbon preferences will also have an important impact on retailers' pricing. When retailers set prices for low-carbon and ordinary products, they will be affected by consumer strategic behaviour and consumers' low-carbon preferences. The result will affect the retailer's profit and sales, and its pricing cannot well guide consumers to choose the products the retailer wants to sell.

Therefore, based on the green differentiated products, this paper analyses the retailer's pricing decisions under the low-carbon preference and strategic behaviour of customers. Retailers make different price decisions according to the different needs of customers, in order to reduce the backlog of inventory or make the best order quantity.

\section{Literature Review}

2.1. Product Pricing Decisions in Low-Carbon Supply Chain. There are many literature studies on low-carbon products at home and abroad; most of them analyse the pricing of enterprises or supply chain from the aspects of low-carbon policy and carbon emission reduction. Guo et al. analysed the impact of the carbon tax rate and consumer carbon sensitivity factor on product pricing and designed a coordinated supply chain of carbon emission reduction cost-benefit sharing contract [9]. And mostly from a supply chain perspective, $\mathrm{Su}$ et al. have constructed a green supply chain pricing decision-making model with different power structures and different forms of subsidies under the context of consumer green preferences [10]. The existing literatures only make pricing decisions from the perspective of low-carbon product supply chains. However, there are not only low-carbon products but also ordinary products in the market. There are no literatures to analyze pricing decisions for green differentiated products $[11,12]$. Consumers' strategic behaviour also has an important impact on product pricing. $\mathrm{Hu}$ and Dai studied consumer behaviour under different low-carbon product pricing strategies. It is found that incumbent manufacturers choose to produce lowcarbon products and retailers choose to sell low-carbon products at high prices are the equilibrium strategy of the game between all parties [13]. Zhang et al. focus on the impacts of consumer environmental awareness (CEA) and retailer's fairness concerns on environmental quality, wholesale price, and retail price of the green product in one manufacturer and one-retailer supply chain $[14,15]$. Xu et al. analyse the renewable energy from the political, technical, economic, and social perspectives $[16,17]$. In order to improve the utilization rate of resources, a fuzzy resource optimal allocation model for multistage stochastic logistics tasks was proposed [18].

2.2. Pricing Decisions of Differentiated Products. There are also many literature studies on the pricing of differentiated products. Because low-carbon products have the same functions as ordinary products [19]. But low-carbon products are priced much higher than ordinary products [20]. Yang et al. studied the differential pricing decision of remanufacturing closed-loop supply chains [21]. Zhou et al. explored the influence of network externalities on the pricing strategy of quality differentiated products [22]. Kalnins studied price changes in the dualchannel supply chain and found that price-based brand externalities have a significant impact on the choice of different quality brand sales channels [23]. Liu and Liu in an environment where low-carbon products and ordinary products coexist, they consider that consumers have differences. Qualitative willingness to pay and consumption utility, research the supply chain's ability to price products and supply chain coordination issues [24]. When one manufacturer produces the two kinds of products, its profit will increase with the increase incarbon trading price through alliance strategy [25]. Luo et al. have studied the location and pricing of products with the same but different sales functions based on the Hotelling model [26]. Li et al. established a secondary supply chain Stackelberg game model consisting of two manufacturers (ordinary product manufacturers and low-carbon product manufacturers) and one retailer to make supply chain decisions [27].

\subsection{Pricing Decisions Based on Strategic Consumers.} There are also many literature studies that examine corporate pricing decisions based on strategic consumers. Both Nair [28] and Li et al. [29] provided empirical evidence for strategic consumers and their purchasing behaviour. Whether in reality or in academia, the impact of consumers' strategic waiting and buying behaviour on business operations cannot be underestimated and ignoring consumers' tactics will bring huge economic losses to the business $[30,31]$. Du et al. found that the behaviour of strategic consumers would have adverse effects on enterprises [32]. Wu et al. considered a retailer's markdown pricing and inventory decisions in multiple seasons where consumers can learn from reference prices to decide when to purchase [33]. Dong and Wu discussed the two-period pricing problem and concluded that when market demand is evenly distributed, strategic consumers may bring more benefits to manufacturers $[34,35]$. But the above research ignores the low-carbon preference factors of strategic consumers. Xinmin Liu et al. distinguished three types of strategic customers according to their different preferences to analyse the optimal pricing and greenness strategies in the sustainable supply chain in strategic customer scenarios [36]. Feng et al. analysed consumer buying habits and constructed a two-stage game model between strategic consumers and retailers [37, 38]. Peng established a retailer optimization model facing homogeneous strategic consumers and used the stochastic optimal response equilibrium model to describe the limited rational behaviour of strategic consumers [39].

The above-mentioned literature analyses the pricing decisions of enterprises and retailers from the aspects of supply chain coordination, differentiated products, consumer strategy, and consumer low-carbon preference. However, there is no specific analysis on the pricing decisions of retailers selling green differentiated products under the low-carbon preference of strategic consumers. Therefore, this article takes into account the practical significance and provides decision support for retailers to determine the optimal product sales price and obtain the maximum sales profit when facing strategic consumers with low-carbon preferences. Based on the above-mentioned literature, this 
article analyses the impact of retailer pricing under the consumer's low-carbon preference strategy behaviour in several aspects. One is the cost. The cost of low-carbon products is much higher than that of ordinary products; the other is consumer demand. Strategic consumers will take into account product cost, patience, and preference for lowcarbon products, which will affect consumers' purchasing behaviour, which in turn affects retailers' pricing decisions.

\section{Model Symbols and Assumptions}

This article considers two situations. In the first model, the retailer only sells low-carbon products. After a certain period of time, some products will not be sold. The retailer will carry out certain price discount activities according to the market to stimulate consumers to consume. This will reduce the overall utility of consumers, and some consumers will wait for the timing of this price adjustment to make a purchase, which is the degree of customer strategy $\beta$.

In the second model, retailers will sell low-carbon products and ordinary products at the same time. In the second stage of the sales period, retailers will adjust the prices of different products, thereby forming a price discount coefficient, which is the degree of consumer strategy. Consumer utility is affected by the price discount coefficient, and consumers' utility for ordinary products is lower than that of lowcarbon products. At the same time, which product the consumers choose is also based on consumers' green preferences.

Figure 1 shows the game sequence of retailers in different markets. Faced with two situations, the retailer pursues how to adjust prices reasonably under the influence of the above factors, and better cater to consumers' expectations, so as to maximize profits. So, this article will use the method of rational expectation equilibrium. Construct consumers' purchasing decision and retailer's pricing decision model so that retailers and customers form a game equilibrium.

In order to facilitate the analysis of the model, without loss of generality, this article is based on the following assumptions:

Assumption 1. A monopolistic retailer sells two alternative products $L$ (low-carbon products) and $N$ (ordinary products) with different configurations. One order is placed at the beginning of the period. The goods are sold in two stages. The first stage is full price sales, and the second stage is discount promotion. Assuming that the total number of consumers in the market is a certain value $\mathrm{N}$, they are all strategic consumers, and each person can only purchase 1 product at most.

Assumption 2. $p_{i j}(i=1,2$, respectively, indicates the first and second sales period and $j=L, N$ indicates low-carbon products and ordinary products, respectively) is the price of the products. $c_{L}$ and $c_{N}$ represent the unit generation costs of low-carbon and ordinary products, respectively. $q_{i j}$ indicates product sales.

Assumption 3. The consumer's willingness to pay is $v$. It obeys the uniform distribution on the interval $[0,1]$, low- carbon preference attributes $\theta, \theta \in(0,1)$, and $(1+\theta) v$ represents consumers' preference for low-carbon products, which means that consumers with low-carbon preference are more inclined to choose low-carbon products.

Assumption 4. Similar to the consumer strategy degree of Zhang [40] and Ma et al. [41] in the literature is $\beta, \beta \in[0,1]$. $\beta$ can represent the consumer's degree of strategy; the larger the $\beta$, the greater the consumer's degree of strategy, and $\beta=$ 0 means the consumer will buy the product immediately. It can also be expressed as an inter-period discount factor. In the model where low-carbon products are sold at the same time as ordinary products, consumers' psychological strategies for ordinary products in the second stage are lower than those of low-carbon products. Assuming that the degree of strategy is $k \beta$, satisfying $0<k<1$.

The symbols and meanings of the parameter variables involved in the article are shown in Table 1.

\section{Model}

4.1. The Situation Where Retailers Only Sell Low-Carbon Products (Model I). Considering that there is only one lowcarbon product in the market, the price of the product changes over time, and the utility of consumers will also change as the price changes. The following uses reverse induction to analyse.

The consumer's utility function is

$$
\begin{aligned}
& U_{1 L}=(1+\theta) v-p_{1 L}, \\
& U_{2 L}=\beta(1+\theta) v-\beta p_{2 L} .
\end{aligned}
$$

In the case where the market only sells low-carbon products, consumers' purchasing decisions will be affected by their own wishes, product green preference, and strategy. When $U_{1 L}>0$ and $U_{1 L}>U_{2 L}$, that is $\left(p_{1 L}-\beta p_{2 L} /(1-\beta)\right.$ $(1+\theta))<v<1$, consumers will choose to purchase the product in the first stage. When $U_{2 L}>0$ and $U_{2 L}>U_{1 L}$, that is $\left(p_{2 L} / 1+\theta\right)<v<\left(p_{1 L}-\beta p_{2 L} /(1-\beta)(1+\theta)\right)$, consumers will wait and see for a period of time and choose to buy in the second stage product.

Therefore, the demand function of low-carbon products in the first and second stages is

$$
\begin{aligned}
& q_{1 L}=N \int_{\left(p_{1 L}-\beta p_{2 L} /(1-\beta)(1+\theta)\right)}^{1} \mathrm{~d} v=N\left(1-\frac{p_{1 L}-\beta p_{2 L}}{(1-\beta)(1+\theta)}\right), \\
& q_{2 L}=N \int_{\left(p_{2 L} / 1+\theta\right)}^{\left(p_{1 L}-\beta p_{2 L} /(1-\beta)(1+\theta)\right)} \mathrm{d} v=N\left(\frac{p_{1 L}-\beta p_{2 L}}{(1-\beta)(1+\theta)}-\frac{p_{2 L}}{1+\theta}\right) .
\end{aligned}
$$

Therefore, the total sales profit of the first and second stages is

$$
\Pi=\left(p_{1 L}-c_{L}\right) q_{1 L}+\left(p_{2 L}-c_{N}\right) q_{2 L}
$$

Find the first-order partial derivative with respect to $p_{1 L}$ and $p_{2 L}$ from equation (3) as follows: 

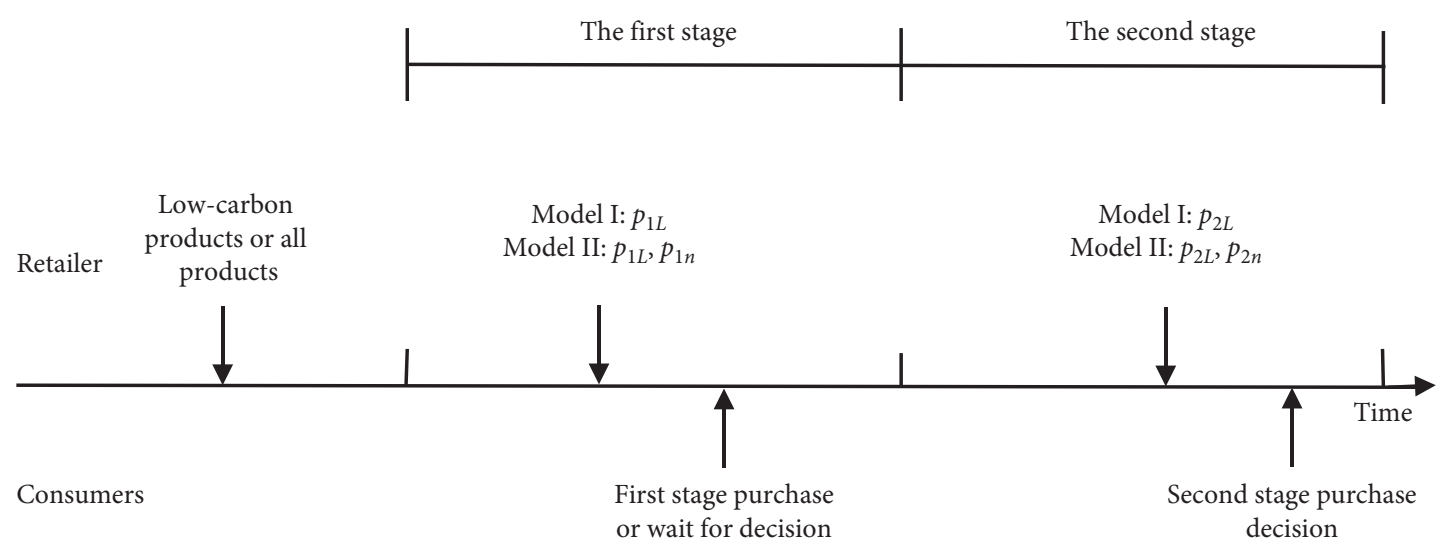

FIgURE 1: Game sequence diagram.

TABLE 1: Main parameters and parameter description.

\begin{tabular}{lc}
\hline Parameters & Definition \\
\hline$v$ & Consumer willingness to pay \\
$\theta$ & $\begin{array}{c}\text { Consumer low-carbon preference attributes } \\
\beta\end{array}$ \\
$N$ & Number of consumers \\
$c_{L}$ & Cost of low-carbon products \\
$p_{1 L}$ & First stage's price of low-carbon products \\
$p_{2 L}$ & Second stage's price of low-carbon products \\
$q_{1 L}$ & First stage's demand of low-carbon products \\
$q_{2 L}$ & Second stage's demand of low-carbon products \\
$\gamma$ & The proportion of products purchased by consumers in the first stage \\
$c_{N}$ & Cost of ordinary products \\
$p_{1 N}$ & First stage's price of ordinary products \\
$p_{2 N}$ & Second stage's price of ordinary products \\
$q_{1 N}$ & First stage's demand of ordinary products \\
$q_{2 N}$ & Second stage's demand of ordinary products \\
$\Pi$ & Total profit \\
\hline
\end{tabular}

$$
\begin{aligned}
& \frac{\partial \Pi_{L}}{\partial p_{1 L}}=N+\frac{N p_{2 L}(1+\beta)-2 N p_{1 L}}{(1-\beta)(1+\theta)}=0, \\
& \frac{\partial \Pi_{L}}{\partial p_{2 L}}=\frac{N p_{1 L}(1+\beta)-2 N p_{2 L}}{(1-\beta)(1+\theta)}+\frac{N c_{L}-2 N p_{2 L}}{1+\theta}=0 .
\end{aligned}
$$

Find the second-order partial derivative of $\Pi_{L}$ with respect to $p_{1 L}$ and $p_{2 L}$ as follows:

$$
\begin{aligned}
& \frac{\partial^{2} \Pi_{L}}{\partial p_{1 L}^{2}}=-\frac{2 N}{(1-\beta)(1+\theta)}, \frac{\partial^{2} \Pi_{L}}{\partial p_{1 L} p_{2 L}}=\frac{N \beta+N}{(1-\beta)(1+\theta)}, \\
& \frac{\partial^{2} \Pi_{L}}{\partial p_{2 L}^{2}}=-\frac{2 N}{(1-\beta)(1+\theta)}, \frac{\partial^{2} \Pi_{L}}{\partial p_{2 L} p_{2 L}}=\frac{N \beta+N}{(1-\beta)(1+\theta)} .
\end{aligned}
$$

Through the above formula, the Hessel matrix of the second-order partial derivatives of $p_{1 L}$ and $p_{2 L}$ can be obtained as follows:

$$
\begin{aligned}
H\left(p_{1 L}, p_{2 L}\right) & =\left[\begin{array}{cc}
-\frac{2 N}{(1-\beta)(1+\theta)} & \frac{N \beta+N}{(1-\beta)(1+\theta)} \\
\frac{N \beta+N}{(1-\beta)(1+\theta)} & -\frac{2 N}{(1-\beta)(1+\theta)}
\end{array}\right], \\
\left|H_{1}\left(p_{1 L}, p_{2 L}\right)\right| & =-\frac{2 N}{(1-\beta)(1+\theta)}, \\
\left|H_{2}\left(p_{1 L}, p_{2 L}\right)\right| & =\frac{N^{2}(3+\beta)}{(1-\beta)(1+\theta)^{2}} .
\end{aligned}
$$

From formula (7), it can be seen that $H_{1}<0$ and $H_{2}>0$. The Hesse matrix is negative definite, which proves that this point is a maximum point.

Let formulas (4) and (5) are equal to 0; the two-stage retail prices of low-carbon products are 


$$
\begin{aligned}
& p_{1 L}^{*}=\frac{2(1+\theta)+(1+\beta) c_{L}}{3+\beta}, \\
& p_{2 L}^{*}=\frac{(1+\theta)(1+\beta)-2 c_{L}}{3+\beta} .
\end{aligned}
$$

According to formulas (8) and (9), the two-stage optimal sales volume of low-carbon products are

$$
\begin{aligned}
& q_{1 L}^{*}=N\left(\frac{1+\theta-c_{L}}{(1+\theta)(3+\beta)}\right), \\
& q_{2 L}^{*}=N\left(\frac{1+\theta-c_{L}}{(1+\theta)(3+\beta)}\right) .
\end{aligned}
$$

According to formulas (8) and (9), the optimal profit of low-carbon products in a single product market is

$\operatorname{MAX\Pi }=N\left(\frac{1+\theta-c_{L}}{(1+\theta)(3+\beta)}\right)\left(\frac{(1+\theta)(3+\beta)-(7+\beta) c_{L}}{(3+\beta)}\right)$.

\section{Proposition 1}

(1) In the first stage, the retail price $p_{1 L}^{*}$ of low-carbon products decreases with the increase of consumer strategy $\beta$, and the retail price $p_{2 L}^{*}$ of low-carbon products in the second stage decreases with the increase in consumer strategy $\beta$.

(2) The retail price of low-carbon products in the first stage $p_{1 L}^{*}$ increases with consumers' green preferencet, and the retail price of low-carbon products in the second stage $p_{2 L}^{*}$ increases with consumers' green preference.

(3) The optimal sales of low-carbon products in the two stages are all about $\beta$ diminishing.

\section{Proof}

(1) Calculate the derivative of $p_{1 L}$ with respect to $\beta$ from formula (8), and obtain $\left(\mathrm{d} p_{1 L}^{*} / \mathrm{d} \beta\right)=\left(2 c_{L}-2 \theta-\right.$ $\left.2 /(3+\beta)^{2}\right)<0$, so low-carbon products are in The retail price $p_{1 L}^{*}$ in the first stage decreases with the increase of consumer strategy $\beta$. Calculate the derivative of $p_{2 L}$ with respect to $\beta$ in formula (9), and obtain $\left(\mathrm{d} p_{2 L}^{*} / \mathrm{d} \beta\right)=\left(2 c_{L}-2 \theta+2 /(3+\beta)^{2}\right)>0$, lowcarbon products in the second stage. The retail price $p_{2 L}^{*}$ increases with the increase inconsumer strategy $\beta$.

(2) Calculate the derivative of $p_{1 L}$ with respect to $\theta$ in formula (8), and obtain $\left(\mathrm{d} p_{1 L}^{*} / \mathrm{d} \theta\right)=(2 / 3+\beta)>0$, and calculate the derivative of $p_{2 L}$ with respect to $\theta$ in formula (9), and obtain $\left(\mathrm{d} p_{2 L}^{*} / \mathrm{d} \theta\right)=(1+\beta / 3$ $+\beta)>0$, so the prices of low-carbon products in both stages will increase with the increase inconsumers' low-carbon preference $\theta$.

(3) Since $q_{1 L}^{*}=q_{2 L}^{*},\left(\mathrm{~d} q_{1 L}^{*} / \mathrm{d} \beta\right)=\left(\mathrm{d} q_{2 L}^{*} / \mathrm{d} \beta\right)=-(N(1+\theta)$ $\left.\left(1+\theta-c_{L}\right) /(\beta+\theta \beta+3+3 \theta)^{2}\right)<0$, so the optimal sales of low-carbon products in the two stages are all about $\beta$ decreasing.

4.2. The Situation Where a Retailer Sells Low-Carbon Products and Ordinary Products at the Same Time (Model II). In the case of low-carbon preference consumers, considering that there are both low-carbon products and ordinary products on the market, the two have formed a situation of mutual competition and substitution. Assuming that consumers have a preference for low-carbon products $\theta,(0<\theta<1)$, and consumers' preference for ordinary products is less than their preference for low-carbon products; the utility function of the first stage of consumers is:

$$
\begin{aligned}
U_{1 L} & =(1+\theta) v-p_{1 L}, \\
U_{1 N} & =v-p_{1 N} .
\end{aligned}
$$

In the first stage, when the market sells both low-carbon products and ordinary products, consumers' purchasing decisions will be affected by their own wishes and preference for green products. Through graph analysis, when consumers' preference for low-carbon products is within the range of $\theta \in(0,1)$, when $U_{1 L}>0$ and $U_{1 L}>U_{1 N}$, consumers' willingness to pay for low-carbon products is $\max$ $\left\{\left(p_{1 L} / 1+\theta\right)<v<\left(p_{1 L}-p_{1 N} / \theta\right)\right\}<v<1, \quad$ when $\left(p_{1 L} / 1+\theta\right)$ $<\left(p_{1 L}-p_{1 N} / \theta\right)$, that is $\left(p_{1 L}-p_{1 N} / \theta\right)<v<1$, consumers will choose to buy low-carbon products. When $U_{1 N}>0$ and $U_{1 N}>U_{1 L}$, that is $p_{1 N}<v<\left(p_{1 L}-p_{1 N} / \theta\right)$, consumers will choose to buy ordinary products. Figure 2 is an analysis using the consumer utility function graph.

According to the consumer utility function, the market demand function is

$$
q_{1 L}=\gamma N \int_{\left(p_{1 L}-p_{1 N} / \theta\right)}^{1} f(v) \mathrm{d} v=\gamma N\left(1-\frac{p_{1 L}-p_{1 N}}{\theta}\right),
$$

$$
q_{1 N}=\gamma N \int_{p_{1 N}}^{\left(p_{1 L}-p_{1 N} / \theta\right)} f(v) \mathrm{d} v=\gamma N\left(\frac{p_{1 L}-p_{1 N}}{\theta}-p_{1 N}\right),
$$

$\gamma$ represents the proportion of consumers who bought the product in the first stage. The profit functions of retailers selling low-carbon products and ordinary products in the first stage are

$$
\Pi_{1 L}=\left(p_{1 L}-c_{L}\right) q_{1 L}=\gamma N\left(p_{1 L}-c_{L}\right)\left(1-\frac{p_{1 L}-p_{1 N}}{\theta}\right),
$$

$$
\Pi_{1 N}=\left(p_{1 L}-c_{N}\right) q_{1 N}=\gamma N\left(p_{1 L}-c_{N}\right)\left(\frac{p_{1 L}-p_{1 N}}{\theta}-p_{1 N}\right) .
$$

If $\left(p_{1 L} / 1+\theta\right)>\left(p_{1 L}-p_{1 N} / \theta\right)$, that is, $\left(p_{1 L} / 1+\theta\right)$ $<v<1$, in this case, the consumer utility of low-carbon products is always higher than that of ordinary products. 


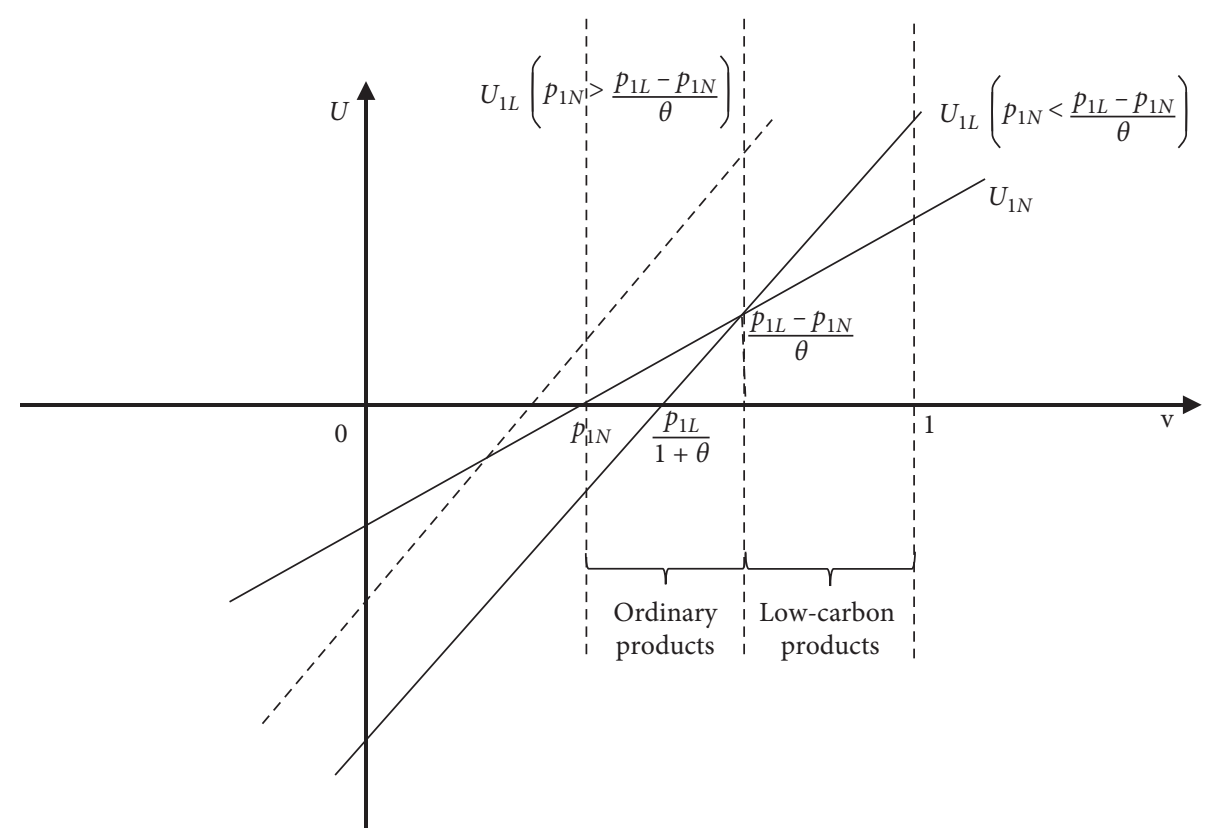

FIgURE 2: Relationship between consumer willingness and utility.

Effectiveness: consumers will definitely choose to buy lowcarbon products, but this kind of situation does not match the actual sales situation, so we will not discuss it.

In the second stage, after a certain period of time sales, consumers will reduce their enthusiasm for the product and make more rational decisions. Strategic consumers will make strategic purchases. At the same time, strategic consumers will be affected by their patience, and their lowcarbon levels are different for different products. Thus, the utility function expression

$$
\begin{aligned}
U_{2 L} & =\beta(1+\theta) v-\beta p_{2 L}, \\
U_{2 N} & =k\left(\beta v-\beta p_{2 N}\right) .
\end{aligned}
$$

When consumers' preference for low-carbon products is within the range of $\theta \in(0,1)$, when $U_{2 L}>0$ and $U_{2 L}>U_{2 N}$, $\max \left\{\left(p_{2 L} / 1+\theta\right),\left(p_{2 L}-k p_{2 N} / 1+\theta-k\right)\right\}<v<1$; similar to the first stage, we do not consider the case of $\left(p_{2 L} / 1+\theta\right)>\left(p_{2 L}-k p_{2 N} / 1+\theta-k\right)$. When $\left(p_{2 L} / 1+\theta\right)<$ $\left(p_{2 L}-k p_{2 N} / 1+\theta-k\right)$, that is $\left(p_{2 L}-k p_{2 N} / 1+\theta-k\right)<$ $v<1$, consumers will choose to buy low-carbon products; when $U_{2 N}>0$ and $U_{2 N}>U_{2 L}$ that is $p_{2 N}<v<\left(p_{2 L}-k p_{2 N}\right.$ $/ 1+\theta-k)$, consumers will choose to buy ordinary products in the second stage.

Therefore, the consumer demand function is

$$
\begin{aligned}
& q_{2 L}=(1-\gamma) N \int_{\left(p_{2 L}-k p_{2 N} / 1+\theta-k\right)}^{1} f(v) \mathrm{d} v=(1-\gamma) N\left(1-\frac{p_{2 L}-k p_{2 N}}{1+\theta-k}\right), \\
& q_{2 N}=(1-\gamma) N \int_{\left(p_{2 L}-k p_{2 N} / 1+\theta-k\right)}^{1} f(v) \mathrm{d} v=(1-\gamma) N\left(\frac{p_{2 L}-k p_{2 N}}{1+\theta-k}-p_{2 N}\right) .
\end{aligned}
$$

The retailer profit function is

$$
\begin{gathered}
\Pi_{2 L}=\left(p_{2 L}-c_{L}\right) q_{2 L}=(1-\gamma) N\left(p_{2 L}-c_{L}\right)\left(1-\frac{p_{2 L}-k p_{2 N}}{1+\theta-k}\right), \\
\Pi_{2 N}=\left(p_{2 N}-c_{N}\right) q_{2 N}=(1-\gamma) N\left(p_{2 N}-c_{N}\right)\left(\frac{p_{2 L}-k p_{2 N}}{1+\theta-k}-p_{2 N}\right) .
\end{gathered}
$$

Combining formulas (15), (16), (20), and (21), the total sales profit of low-carbon products and ordinary products in the first and second stages is

$$
\Pi=\Pi_{1 L}+\Pi_{1 N}+\Pi_{2 L}+\Pi_{2 N}
$$

In order to maximize the profit, find the first-order partial derivatives of $p_{1 L}, p_{1 N}, p_{2 L}$, and $p_{2 N}$ for equation (22) as follows: 


$$
\begin{aligned}
\frac{\partial \Pi_{L}}{\partial p_{1 L}} & =\frac{\gamma N\left(\theta-2 p_{1 L}+c_{L}+2 p_{1 N}\right)}{\theta}, \\
\frac{\partial \Pi_{L}}{\partial p_{1 N}} & =\frac{\gamma N\left(2 p_{1 L}-c_{L}-2 p_{1 N}-2 \theta p_{1 N}+\theta c_{N}+c_{N}\right)}{\theta}, \\
\frac{\partial \Pi_{L}}{\partial p_{2 L}} & =\frac{(1-\gamma) N\left(1+\theta-k-2 p_{2 L}+c_{L}+k p_{2 N}+p_{2 N}-c_{N}\right)}{1+\theta-k}, \\
\frac{\partial \Pi_{L}}{\partial p_{2 N}} & =\frac{(1-\gamma) N\left(k p_{2 L}-k c_{L}+p_{2 L}-2 p_{2 N}-2 \theta p_{2 N}+c_{N}+\theta c_{N}\right)}{1+\theta-k} .
\end{aligned}
$$

The two-stage optimal retail prices of the two products obtained by the first-order partial derivative are

$$
\begin{aligned}
& p_{1 L}^{*}=\frac{1+\theta+c_{L}}{2}, \\
& p_{1 N}^{*}=\frac{1+c_{N}}{2}, \\
& p_{2 L}^{*}=\frac{\left(-k^{2}-k+2+2 \theta\right) c_{L}+(k+k \theta-1-\theta) c_{N}-2 k+2 \theta^{2}-2 \theta k+2+4 \theta}{3+4 \theta-k^{2}-2 k}, \\
& p_{2 N}^{*}=\frac{(1-k) c_{L}+(1+2 \theta-k) c_{N}-k^{2}+\theta k+1+\theta}{3+4 \theta-k^{2}-2 k} .
\end{aligned}
$$

Take the above formula into (13), (14), (18), and (19) to get the optimal sales volume as follows:

$$
\begin{aligned}
q_{1 L}^{*}= & \gamma N\left(1-\frac{\theta+c_{L}-c_{N}}{2 \theta}\right), \\
q_{1 N}^{*}= & \gamma N\left(\frac{c_{L}-c_{N}-\theta c_{N}}{2 \theta}\right), \\
q_{2 L}^{*}= & (1-\gamma) N\left(1-\frac{(2+2 \theta-2 k) c_{L}+\left(k^{2}-\theta k-1-\theta\right) c_{N}}{\left(3+4 \theta-k^{2}-2 k\right)(1+\theta-k)}\right. \\
& -\frac{-3 k+2 \theta^{2}-3 \theta k+2+4 \theta+k^{3}-\theta k^{2}}{\left(3+4 \theta-k^{2}-2 k\right)(1+\theta-k)}, \\
q_{2 N}^{*}= & (1-\gamma) N\left(\frac{(2+2 \theta-2 k) c_{L}+\left(k^{2}-\theta k-1-\theta\right) c_{N}}{\left(3+4 \theta-k^{2}-2 k\right)(1+\theta-k)}\right. \\
& +\frac{-3 k+2 \theta^{2}-3 \theta k+2+4 \theta+k^{3}-\theta k^{2}}{\left(3+4 \theta-k^{2}-2 k\right)(1+\theta-k)} \\
& \left.-\frac{(1-k) c_{L}+(1+2 \theta-k) c_{N}-k^{2}+\theta k+1+\theta}{3+4 \theta-k^{2}-2 k}\right) .
\end{aligned}
$$


Substituting equations (24)-(31) into equation (22), the total profit of low-carbon products and ordinary products in the two stages is

$$
\begin{aligned}
\Pi^{*}= & \gamma N\left(1-\frac{\theta+c_{L}-c_{N}}{2 \theta}\right)\left(\frac{1+\theta+c_{L}}{2}-c_{L}\right)+\gamma N\left(\frac{c_{L}-c_{N}-\theta c_{N}}{2 \theta}\right)\left(\frac{1+c_{N}}{2}-c_{N}\right) \\
& +(1-\gamma) N\left(\frac{\left(-k^{2}-k+2+2 \theta\right) c_{L}+(k+k \theta-1-\theta) c_{N}-2 k+2 \theta^{2}-2 \theta k+2+4 \theta}{3+4 \theta-k^{2}-2 k}-c_{L}\right) \\
& \cdot\left(1-\frac{(2+2 \theta-2 k) c_{L}+\left(k^{2}-\theta k-1-\theta\right) c_{N}}{\left(3+4 \theta-k^{2}-2 k\right)(1+\theta-k)}-\frac{-3 k+2 \theta^{2}-3 \theta k+2+4 \theta+k^{3}-\theta k^{2}}{\left(3+4 \theta-k^{2}-2 k\right)(1+\theta-k)}\right) \\
& +(1-\gamma) N \frac{(2+2 \theta-2 k) c_{L}+\left(k^{2}-\theta k-1-\theta\right) c_{N}}{\left(3+4 \theta-k^{2}-2 k\right)(1+\theta-k)}+\frac{-3 k+2 \theta^{2}-3 \theta k+2+4 \theta+k^{3}-\theta k^{2}}{\left(3+4 \theta-k^{2}-2 k\right)(1+\theta-k)} \\
& -\frac{(1-k) c_{L}+(1+2 \theta-k) c_{N}-k^{2}+\theta k+1+\theta}{3+4 \theta-k^{2}-2 k}\left(\frac{(1-k) c_{L}+(1+2 \theta-k) c_{N}-k^{2}+\theta k+1+\theta}{3+4 \theta-k^{2}-2 k}-c_{N}\right) .
\end{aligned}
$$
get

Analysing the optimal solution in this situation, we can

\section{Proposition 2}

(1) In the first stage, the retail price $p_{1 N}$ of ordinary products has nothing to do with the customer's greenness $\theta$ of low-carbon products, while the retail price $p_{1 L}$ of low-carbon products increases with the increase in $\theta$. In the second stage, $p_{2 L}$ increases with the increase in $\theta . p_{2 N}$ decreases as $\theta$ increases.

(2) In the first stage, the sales volume of low-carbon products $q_{1 L}^{*}$ increases as $\theta$ increases. The sales volume of ordinary products $q_{1 N}^{*}$ decreases with the increase in $\theta$. In the second stage, the sales volume of lowcarbon products increases with the increase in $\theta$, and the sales volume of ordinary products decreases with the increase in $\theta$.

\section{Proof}

(1) From equation (25), $p_{1 N}$ has nothing to do with $\theta$. Calculating the derivative of $p_{1 L}^{*}$ with respect to $\theta$ in equation $(24)$ is $\left(\mathrm{d} p_{1 L} / \mathrm{d} \theta\right)=(1 / 2)>0$, so $p_{1 L}$ increases as $\theta$ increases. Calculating the derivative of $p_{2 L}^{*}$ with respect to $\theta$ in equation $(26)$ is $\left(\mathrm{d} p_{2 L} / \mathrm{d} \theta\right)=$ $-\left(\left(c_{N}-2\right) k^{3}+\left(4 \theta+c_{N}-2 c_{L}\right) k^{2}+\left(8 \theta^{2}+4\right) k-8 \theta^{2}\right.$ $-8 \theta-2 c_{N}+4 c_{L} / k^{4}+4 k^{3}-8 \theta k^{2}+\left(-16 \theta^{2}-8\right) k+$ $\left.16 \theta^{2}+16 \theta+4\right)>0$; find $p_{2 L}^{*}$ for equation (27). The derivative of $\theta$ is $\left(\mathrm{d} p_{2 N} / \mathrm{d} \theta\right)<0$; so in the second stage, $p_{2 L} p_{2 L}$ increases with the increase in $\theta . p_{2 N}$ decreases as $\theta$ increases.

(2) Calculating the derivative of $q_{1 L}^{*}$ with respect to $\theta$ from equation (28) is $\left(\mathrm{d} q_{1 L}^{*} / \mathrm{d} \theta\right)=(\gamma N$ $\left.\left(c_{L}-c_{N}\right) / 2 \theta^{2}\right)>0$. Therefore, the sales volume of low-carbon products in the first stage increases with the increase in customers' green preference. $\left(\mathrm{d} q_{1 N}^{*} / \mathrm{d} \theta\right)=\left(\gamma N\left(c_{N}-c_{L}\right) / 2 \theta^{2}\right)<0$, so, the sales volume of ordinary products in the first stage decreases with the increase in customers' green preference. In the second stage, the sales volume of lowcarbon products decreases with the increase in $\theta$, and the proposition that the sales volume of ordinary products increases with the increase in $\theta$ will be verified in the numerical analysis in Chapter 5.

\section{Numerical Analysis}

\subsection{Model I}

5.1.1. The Influence of Parameter $\beta$ on Product Price. Assuming $c_{L}=0.3, \beta \in(0,1), \theta \in(0,1), N=1000$, and $c_{N}=0.2$, study the influence of parameter $\beta$ on the price of low-carbon products. From Figure 3 , it is found that given a value of $\theta$, the price of low-carbon products decreases with the increase in $\beta$ in the first stage, and increases with the increase in $\beta$ in the second stage. It shows that in the first stage, the greater the degree of customer strategy, the lower the price. In the second stage, the greater the degree of customer strategy, the greater the price. And the second stage is more affected by $\theta$ than the first stage.

5.1.2. The Influence of Parameters $\beta$ and $\theta$ on Total Profit. In the Figure 4 , given the value of $\beta$, study the effect of $\theta$ on total profit. It is found that the influence of customers' low-carbon preference on profit is positive, and the total profit will increase with the increase in $\theta$. Given the value of $\theta$, study the effect of $\beta$ on total profit and found that the impact of customer strategy on total profit is negative. The greater the customer strategy, the lower the total profit. This is because customers choose the time to purchase based on their own utility maximization. For retailers at this time, the price is lower and may cause a certain inventory cost. 


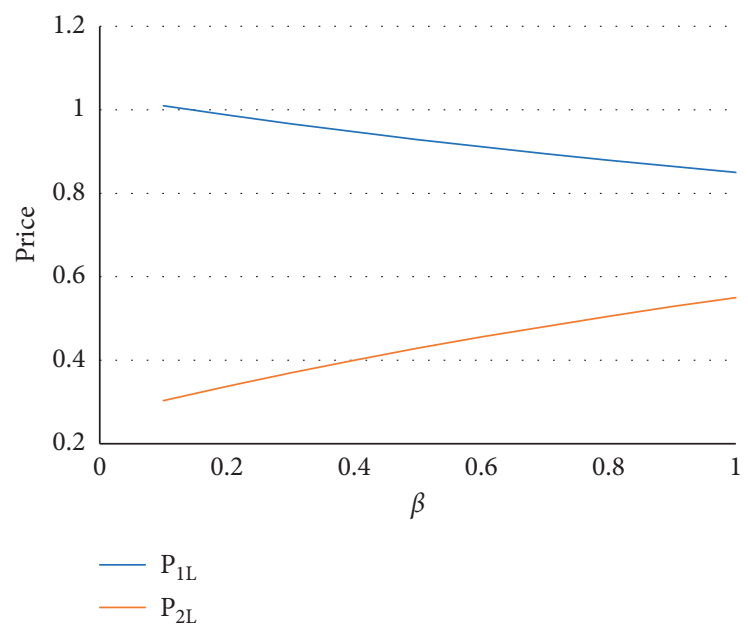

FIgURE 3: The influence of parameter $\beta$ on product price.

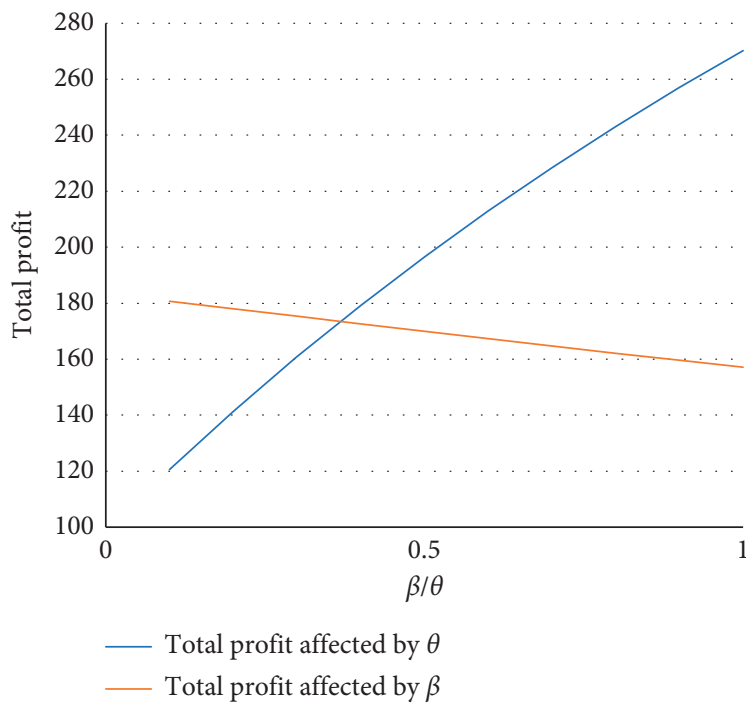

Figure 4: The influence of parameters $\beta$ and $\theta$ on total profit.

5.2. Model II. Assuming $c_{L}=0.3, \beta \in(0,1), \theta \in(0,1)$, $N=1000$, and $c_{N}=0.2, \gamma=0.4$. As the Figure 5 shows that given a $\beta$ value and a $k$ value to studies the influence of the price of each stage of parameter $\theta$. It was found that consumers' low-carbon preference has a positive effect on lowcarbon products' demand and has a slight negative effect on ordinary products' demand. In the first stage, consumers' low-carbon preferences have a more significant impact on demand, while the second stage is relatively flat.

Consider $\theta=0.2,0.4,0.6$, and 0.8 to study the influence of parameter $k$ on the total profit of the two stages. As the Figure 6 shows that given the values of $\beta$ and $\theta$, the total profits of the two stages will increase as the difference in discount strength between the two products increases. When the value of $k$ is larger, the retailer's total profit is smaller, and the two products are negatively correlated. That is, when the intertemporal discount coefficient of consumers in the second stage of ordinary products is larger, the retailer's total profit is smaller. Therefore, for retailers, only two products with similar discount strength can increase total profit. When we give the value of $k$, we find that the retailer's total profit increases as consumers' low-carbon preference increases. In other words, the greater the customer's green preference, the more beneficial to the retailer. Consumers' green preference means that consumers are more willing to buy low-carbon products. In the first stage, the price of ordinary products has nothing to do with green preference, while the price of low-carbon products increases with the increase in $\theta$, which leads to increased profits for retailers. 


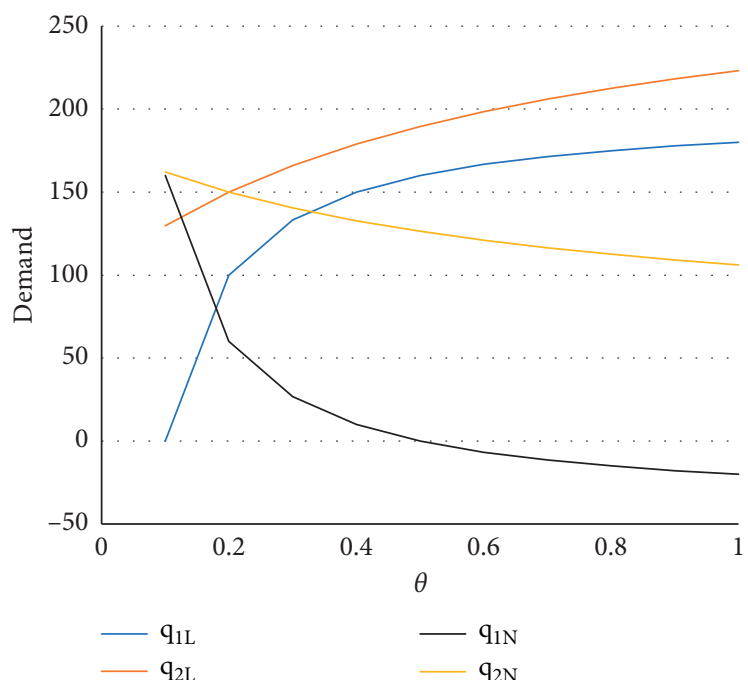

Figure 5: The influence of parameters $\theta$ on demand.

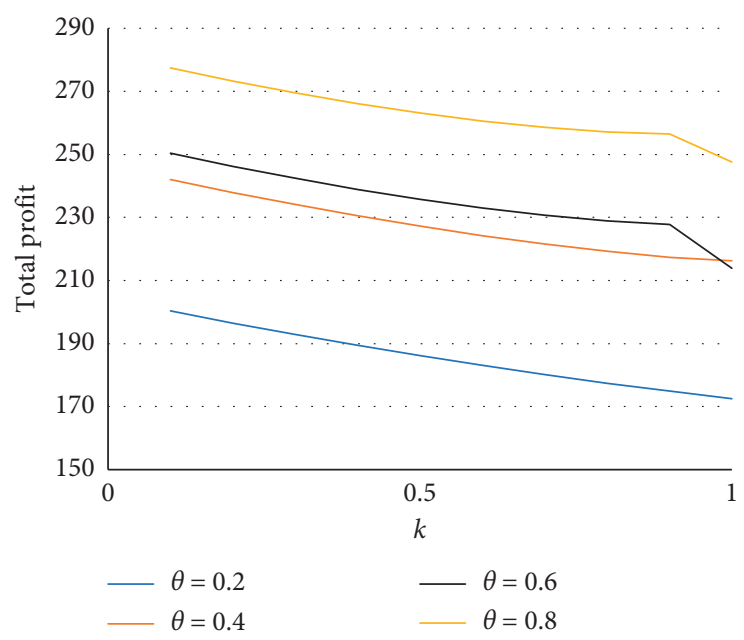

FIgURE 6: The influence of parameters $\mathrm{k}$ on total profit.

\section{Conclusions and Discussion}

This paper studies the two-stage pricing model of green differentiated products based on customer strategic behaviour. First, it analyses the two-stage sales market where there is only one low-carbon product and finds the optimal pricing decision and the optimal sales volume at each stage. The study found

(1) The price of low-carbon products in the first stage decreases as the customer's strategy degree increases, and the price of low-carbon products in the second stage increases as the customer's strategy degree increases.

(2) The sales volume of low-carbon products in the two phases is the same and decreases with the increase in customer strategy.
(3) The total profit of two-stage sales of low-carbon products also decreases with the increase in customer strategy.

Secondly, the two-stage pricing model with low-carbon and ordinary products is studied. The study found

(1) The retail price of ordinary products in the first stage has nothing to do with customers' green preference $\theta$, while the retail price of low-carbon products increases with respect to $\theta$. In the second stage, the retail prices of low-carbon and ordinary products are all $\theta$ increasing.

(2) The demand for low-carbon products in both stages increases with the increase in consumers' low-carbon preference, while the demand for ordinary products is the opposite. 
(3) The total profit of the two stages increases with the increase in $\theta$, and the greater the intertemporal discount factor $\beta$ of consumers for ordinary products in the second stage compared with low-carbon products, the smaller the retailer's total profit.

Therefore, there are the following inspirations for retailers:

In Model 1, consumers' low-carbon preference is positively correlated with retailers' prices and profits, and the degree of consumer strategy has a greater impact on retailers. The higher the degree of consumer strategy, that is to say, the greater the retailer's discount, the more consumers prefer to buy in the second stage. In order to maintain the retailer's overall profit, the retailer's price should be maintained at an appropriate level, and consumers should be encouraged to buy products in the first stage through advertising and other means. Secondly, do not discount or make the discount too large; because if the discount is too strong, the consumer's strategy level will increase, which will reduce the retailer's profit.

In Model II, consumers' green preference has a huge impact on retailers' profits. Retailers can improve consumers' low-carbon preference through the following points. First, increase publicity and promote low-carbon knowledge through posters, advertisements, and publicity boards. Second, mark the carbon footprint of a product for consumers to understand and choose. Third, implement green packaging for products. Fourth, promote a low-carbon economic model.

The greater the difference in discount strength between the two products, the smaller the retailer's profit. Therefore, retailers should reduce the discount difference between lowcarbon and ordinary products, and the greater the green preference of consumers, the greater the total profit. When retailers are selling two products, they can promote consumers' green preferences through advertising and so on, so as to encourage consumers to buy more low-carbon products.

The research of this article can be expanded from the following aspects. This article studies the retailer's pricing decision under the low-carbon preference consumer strategy, but does not involve the perspective of the supply chain. The subsequent research can start from the coordination of the entire supply chain.

\section{Data Availability}

The data used to support the findings of this study are available from the corresponding author upon request.

\section{Conflicts of Interest}

The authors declare that there are no conflicts of interest regarding the publication of this paper.

\section{Acknowledgments}

This research was funded by the Qingdao Social Science Planning Research Project (QDSKL1901037), the
Fundamental Research Funds for the Central Universities (19CX04010B), and the Shandong Soft Science Research Program General Project (2020RKE28013).

\section{References}

[1] F. Gao and X. Su, "Omnichannel retail operations with buyonline-and-pick-up-in-store," Management Science, vol. 63, no. 8, pp. 2478-2492, 2017.

[2] W. Zhang, M. Zhang, W. Zhang, Q. Zhou, and X. Zhang, "What influences the effectiveness of green logistics policies? a grounded theory analysis," Science of the Total Environment, vol. 714, no. 714, Article ID 136731, 2020.

[3] T. T. Wang and D. P. Wang, "The dynamic coordination strategy of supply chain cooperation and low-carbon publicity under government subsidies," Operations Research and Management, vol. 29, no. 8, pp. 52-61, 2020.

[4] M. Laroche, J. Bergeron, and G. Barbaro-Forleo, "Targeting consumers who are willing to pay more for environmentally friendly products," Journal of Consumer Marketing, vol. 18, no. 6, pp. 503-520, 2001.

[5] L. Wang, T. J. Xu, and L. H. Qin, "A study on supply chain emission-reduction level based on carbon tax and consumers' low-carbon preferences under stochastic demand," Mathematical Problems in Engineering, vol. 201920 pages, Article ID 1621395, 2019.

[6] F. Z. Zhang, "Application prospect of STF technology in braking field," International Journal of Plant Engineering and Management, vol. 24, no. 2, pp. 109-114, 2019.

[7] L. C. Liu and X. Zhai, "The optimal innovation and pricing strategy of enterprises facing strategic consumers," Chinese Journal of Management Science, pp. 1-13, 2020, In press.

[8] C. X. Wang, Q. P. Zhang, and W. Zhang, "Corporate social responsibility, green supply chain management and firm performance: the moderating role of big-data analytics capability," Research in Transportation Business \& Management, vol. 37, no. 4, Article ID 100557, 2020.

[9] J. H. Guo, L. Y. Sun, C. Zhang, M. Ni, and J. X. Zhu, "Supply chain pricing and coordination considering consumers' lowcarbon preference under carbon tax policy," Systems Engineering, pp. 1-14, 2020, In press.

[10] C. Su and X. Liu, "Green supply chain decisions considering consumers' low-carbon awareness under different government subsidies," Sustainability, vol. 12, no. 6, p. 2281, 2020.

[11] C. Q. Xu, D. Z. Zhao, and B. Y. Yuan, "Research on differential pricing and coordination mechanism of supply chain in low carbon environment," Operations Research and Management Science, vol. 24, no. 1, pp. 19-26, 2015.

[12] C. Che, W. Q. Ma, and S. F. Cao, "Research on time distance, social distance and the effect of online shopping decision framework," Commercial Research, vol. 9, pp. 130-136, 2015.

[13] P. Hu and Y. H. Dai, "Research on pricing strategy of lowcarbon supply chain based on consumer behaviour," Soft Science, vol. 32, no. 8, pp. 73-90, 2018.

[14] L. H. Zhang, Zhou, Y. Y. Liu, and R. Lu, "Optimal environmental quality and price with consumer environmental awareness and retailer's fairness concerns in supply chain," Journal of Cleaner Production, vol. 213, 2019.

[15] X. F. Xu, Z. Lin, and J. Zhu, "DVRPLS with variable neighbourhood region in refined oil distribution," Annals of Operations Research, 2020, In press.

[16] X. Xu, Z. Wei, Q. Ji, C. Wang, and G. Gao, "Global renewable energy development: influencing factors, trend predictions 
and countermeasures," Resources Policy, vol. 63, no. 10, Article ID 101470, 2019.

[17] X. Xu, J. Hao, and Y. Zheng, "Multi-objective artificial bee colony algorithm for multi-stage resource leveling problem in sharing logistics network," Computers \& Industrial Engineering, vol. 142, no. 4, Article ID 106338, 2020.

[18] X. Xu, J. Hao, L. Yu, and Y. Deng, "Fuzzy optimal allocation model for task-resource assignment problem in a collaborative logistics network," IEEE Transactions on Fuzzy Systems, vol. 27, no. 5, pp. 1112-1125, 2019.

[19] Y. D. Li, L. J. Xia, and F. Z. Wang, "Game and coordination model of low-carbon supply chain based on product substitution," Chinese Journal of Management Science, vol. 27, no. 10, pp. 66-76, 2019.

[20] M. W. Liu, K. L. Wu, H. Fu, and M. Z. Xu, "Retailer-led supply chain cooperation and coordination of emission reduction under consumer low-carbon preference," Systems Engineering-Theory \& Practice, vol. 37, no. 12, pp. 3109-3117, 2017.

[21] A. F. Yang, A. Chen, X. J. Hu, and H. H. Yang, "The optimal pricing model of new products and remanufactured products in a two-stage closed-loop supply chain," Mathematics in Practice and Theory, vol. 48, no. 12, pp. 1-10, 2018.

[22] X. W. Zhou, D. Cai, S. G. Li, Y. J. Zhou, and X. H. Chen, "Product pricing strategy based on network externality and quality differentiation," Journal of Management Sciences in China, vol. 22, no. 8, pp. 1-16, 2019.

[23] A. Kalnins, "Pricing variation within dual-distribution chains: the different implications of externalities and signaling for high- and low-quality brands," Management Science, vol. 63, no. 1, pp. 139-152, 2017.

[24] J. L. Liu and M. W. Liu, "Low-carbon supply chain pricing and coordination strategies for heterogeneous consumers," Journal of Commercial Economics, vol. 3, pp. 47-49, 2019.

[25] Y. Hao, C. Tian, and C. Wu, "Modelling of carbon price in two real carbon trading markets," Journal of Cleaner Production, vol. 244, 2020.

[26] Y. Luo, S. Tu, T. G. Peng, and J. Wei, "Research on location and pricing of differential products with purchase elasticity," Acta Scientiarum Naturalium Universitatis Nankaiensis, vol. 4, pp. 78-82, 2007.

[27] Y. B. Li, C. X. Wang, and D. D. Zhang, "Supply chain decisionmaking for competition between ordinary and low-carbon products under fair preference," Journal of Shanghai Maritime University, vol. 41, no. 3, pp. 66-72, 2020.

[28] H. Nair, "Intertemporal price discrimination with forwardlooking consumers: application to the US market for console video-games," Quantitative Marketing and Economics, vol. 5, no. 3, pp. 239-292, 2007.

[29] J. Li, N. Granados, and S. Netessine, "Are consumers strategic? structural estimation from the air-travel industry," Management Science, vol. 60, no. 9, pp. 2114-2137, 2014.

[30] G. P. Cachon and P. Feldman, "Price commitments with strategic consumers: why it can be optimal to discount more frequently than optimal," Manufacturing \& Service Operations Management, vol. 17, no. 3, pp. 300-410, 2015.

[31] A. K. Parlaktürk, "The value of product variety when selling to strategic consumers," Manufacturing \& Service Operations Management, vol. 14, no. 3, pp. 371-385, 2012.

[32] J. Du, J. Zhang, and G. Hua, "Pricing and inventory management in the presence of strategic customers with risk preference and decreasing value," International Journal of Production Economics, vol. 164, pp. 160-166, 2015.
[33] D. D. Wu, "Selling to the socially interactive consumer: order more or less?" IEEE Transactions on Systems, Man, and Cybernetics: Systems, vol. 45, no. 3, pp. 399-410, 2015.

[34] J. Dong and D. Wu, "Two-period pricing and quick response with strategic customers," International Journal of Production Economics, vol. 215, pp. 165-173, 2017.

[35] C. Che, X. L. Qi, W. Q. Ma, and D. X. Shao, "An empirical study on the influencing factors of mobile social network marketing effectiveness," Chinese Journal of Management Science, vol. 25, no. 5, pp. 145-149, 2017.

[36] X. Liu, K. Lin, L. Wang, and L. Ding, "Pricing decisions for a sustainable supply chain in the presence of potential strategic customers," Sustainability, vol. 12, no. 4, p. 1655, 2020.

[37] J. Feng, B. Liu, and Z. F. Liu, "Research on product dynamic pricing decision based on the purchase habits of strategic consumers," Mathematics in Practice and Theory, vol. 49, no. 13, pp. 18-29, 2019.

[38] C. Che, W. P. Luo, and X. L. Qi, "The influence of space and social distance on the online word-of-mouth valence of virtual communities," Soft Science, vol. 31, no. 4, pp. 117-121+144, 2017.

[39] F. Peng, "Discussion on the influencing factors of retailers' decisions: based on the perspective of strategic consumer behaviour," Journal of Commercial Economics, vol. 24, pp. 28-31, 2019.

[40] L. H. Zhang, Y. W. Kong, and J. Y. Wang, "Two-stage production game equilibrium based on the low-carbon preference of strategic consumers," Computer Integrated Manufacturing System, pp. 1-14, 2020, In press.

[41] P. Ma, W. J. Du, and H. Y. Wang, "Research on the two-stage pricing model of differential products under the customer strategic behaviour," Chinese Journal of Management Science, vol. 28, no. 2, pp. 136-144, 2020. 